\title{
The Development of Officer Selection System using the Method of Analytic Network Process (ANP) at Pharmacy Company
}

\author{
Alexander Setiawan ${ }^{*}$, Andreas Handojo ${ }^{*}$, Olivia Gozali \\ Informatics Engineering, Faculty of Industrial Technology, Petra Christian University \\ Siwalankerto 121 - 131 Surabaya 60236, Indonesia
}

\begin{abstract}
In this life, every person is always faced with various options and each choice will certainly bring different consequences. Pharmacy Company as an organization which managed by the human resources are also faced with various options in order to determine a quality officer. The hardest thing in making a choice is an effort to eliminate the subjectivity factor of the procurement team so that every choice made is objective.

Based on the analysis of the above requirements, the company need a computer application that can support decision making using the Analytic Network Process. The application is not a key decision makers who will replace the role of men but only as decision support.

Applications are made to assist the Personnel Manager of the company in selecting prospective employees and new employee selection. In addition, the application also help in a structured data collection so that support a balanced and objective assessment.
\end{abstract}

Index Terms: Decision Support Systems, Analytical Network Process, Employee, Criteria.

(C) 2016 Published by MECS Publisher. Selection and/or peer review under responsibility of the Research Association of Modern Education and Computer Science.

\section{Introduction}

In modern this, the development of computer technology has developed fast. Computer technology was often used by many people because this technology often gave the benefit, for example to be able to be used as means of helping in resolving a problem or decision making. The example of the use of the computer as means for decision making for example for the selection system of acceptance of the prospective official and the rise in the position of the official from the official just became the permanent employee in a company.

The selection of acceptance of the official in a company, was one of the functions that was important in determining the quality of human resources in the company. That was caused by all the work was managed and done by the officials. The official must have competence in the work that will be done by him. If the

\footnotetext{
* Corresponding author. Tel.: (+62) 816541 1487; fax: (+62)31-8417658

E-mail address: alexander@petra.ac.id, handojo@petra.ac.id
} 
acceptance mistake of the official happening, then will result in not more maximal him the achievement of the official and could not support the company to achieve the aim.

The matter above currently was dealt with by the company that was named pharmacy company. This company was involved in the production of the medicine, among them the pharmacy product, traditional medicine, and the supplement to food. The company that consisted of 12 departments and has 100 employees, usually opened the work vacancy totalling 2 times in one year.

In the process of acceptance of the new official, the company used five test kinds, that is the interview test, the Intelligence Quotient test (IQ), the Dominance Influence Steadiness Conscientiousness identity test (the DISC), the honesty test of Honesty and Integrity Pre- Employment Tests (HIPET) especially to sales and the Curriculum Vitae test (CV). After through various tests, the official just underwent the probationary period for 3 months, before becoming the company's permanent employee. The process of the rise in this position used several criteria, among them responsibility, knowledge, communication, the capacity took the decision and discipline. The hardest matter in making the choice be efforts to eliminate the factor subjectivity from the Personnel Manager so as each choice that was made be objective with be based on in criteria that were hoped for by the company. This made the company feel necessary to use help of computer technology to help in more objective decision making [1].

To overcome this problem, then to this research will be made by a selection system of acceptance and the rise in the position of the official used the Analytic Network Process method [1]. His aim so that this system could help the company in decision making to receive his official in accordance with the specification of the work that was needed and could help determined the rise in the position from the official just became the permanent employee. The formulation of the problem that was received to this research that is

- How made an application that could help see the potential for the prospective official to occupy a certain position.

- How made the database plan that could keep the data of the official's candidate.

- How made an application that could help the company in taking the decision to recruit the prospective official and determine the rise in the position of this new official to the permanent employee

The aim of this research was to make the application of the selection system of acceptance and the rise in the position of the official use the Analytic Network Process method. This application could produce the alternative to the decision of the election of the official's candidate that was objective as well as in accordance with the criterion that was needed by the company [2].

\section{Analytical Network Process Method}

The Analytic Network Process method (ANP) was the development of the Analytical Hierarchy Process (AHP). The ANP method of could improve the AHP weakness took the form of the capacity accommodates the connection between the criterion or the alternative $[3,4]$. The connection in the ANP method of having 2 kinds that is the connection in one set of the element (inner dependence) and the connection between the different element (outer dependence). The existence of this connection caused the ANP method more complex compared with the AHP method $[7,8]$.

The ANP is a generic form of AHP and allows for more complex interdependent relationships among elements [6]. It is also known as the systems-with-feedback approach [5]. Inter-dependence can occur in several ways: (1) uncorrelated elements are connected, (2) uncorrelated levels are con-nected and (3) dependence of two levels is two-way (i.e.bi-directional). Fig. 1. Illustrates examples of these interdependencies. By incorporating interdependencies [4]. 


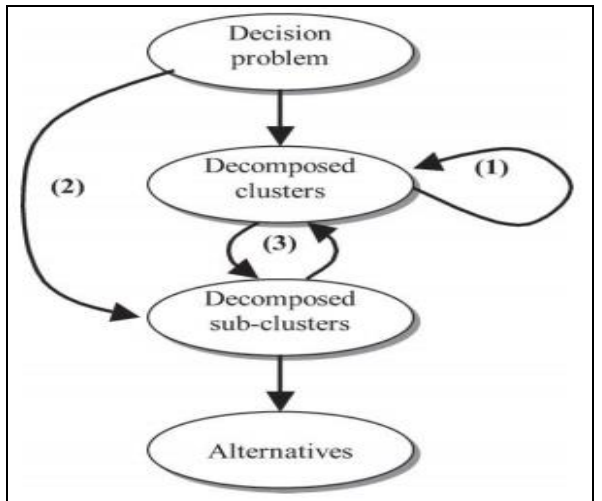

Fig.1. Examples of Interdependence

\section{System Design}

The Steps in the execution of the research:

- The study of Literature

- Studied about Microsoft Visual Basic .Net 2005 and Oracle 10g.

- Studied the Analytic Network Process theory (ANP).

- The analysis of the Problem and the Analysis of the Requirement

- Analysed the long system that was used by the company.

- Analysed any that were needed in the production of the application.

- The production of Software

- System planning and the production of the design of the interface.

- The production of the ANP calculation system.

- Testing and Analysis

- The Testing of the application that was made.

- The Analysis of results output of the application.

- The conclusion and the suggestion from the planning activity and the production of the ANP system.

- Creating Report

Made the report concerning the system and the activity that were carried out in the production of the research. Was based on observation that was carried out towards the selection system of the prospective official company, the available problem that is the difficulty chose the official who was most exact from the prospective official that applied. The difficulty happened in considering the potential for the prospective official for a position but also in the rise in the position of the official just became the permanent employee. The assessment was more often carried out was based on the experience so as the assessment that was made be subjective. More over his data collection system only took the form of the document was written, so as to cause difficulties for the strage and the search for the data.

From the problem that emerged, then several matters along with this was needed by HRD in the production of the supporting system of decision making, in part: 
- Was needed a system connected with the database that could keep the data and the assessment data of the official's candidate towards the criterion and the sub-criterion that were considered, so as if at any time the company needed manpower could make use of the data that was owned beforehand.

- Was needed a system that could support decision making objectively in the selection of the prospective official by means of putting forward the value of the comparison between the prospective official.

- Was needed the application that could produce results of the end of taking the form of the name of the prospective official who was suitable to occupy the work vacancy that was available but also the name of the new official who will rise the position to the permanent employee.

In planning of the data flow in this information system, the writer used the Data Flow Diagram method (DFD). DFD this information system was begun from DFD context the diagram to DFD the level 1. The context model Data Flow Diagram could be seen in the Fig. 2.

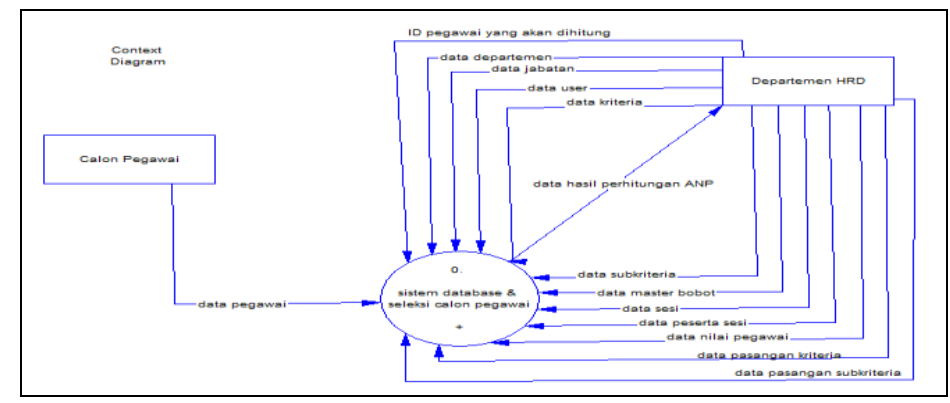

Fig.2. Context Model Data Flow Diagram

Along with this was the data Current in the system mining in the form of DFD that was the explanation from the Figure 1. In DFD this was gotten by 6 processes that will be it was explained further that is the process input the official's data, the process input the session data, the process input participants' data in the session, the process input the data the value of the official, the process input the user's data, and the Process of the selection of the official with ANP. Data Flow Diagram could be seen in the Fig. 3.

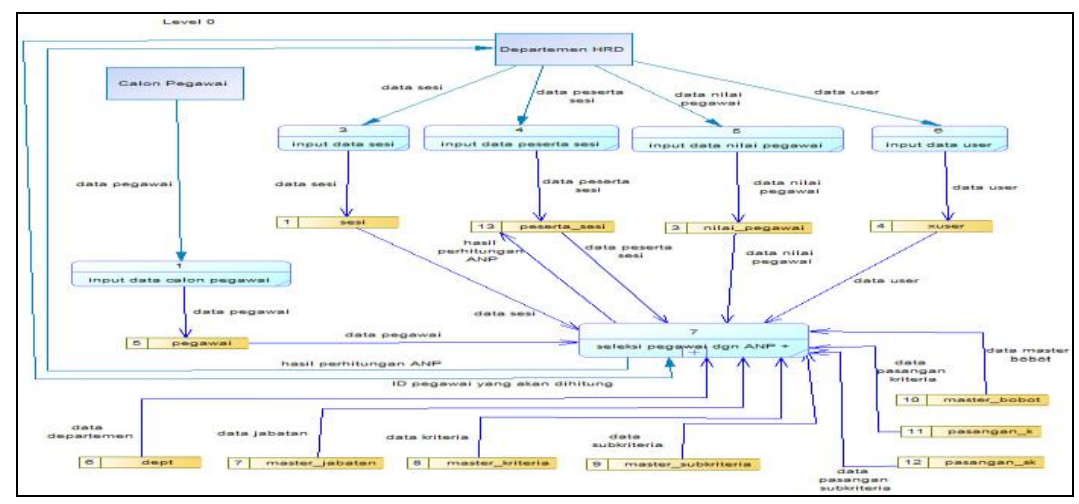

Fig.3. Data Flow Diagram Analytic Network Process (ANP)

From DFD the level 0, the process of the selection of the prospective official was with ANP clarified by dividing the seventh process into two sub the process to DFD the level 1. To clearer could be seen in Fig. 4. 


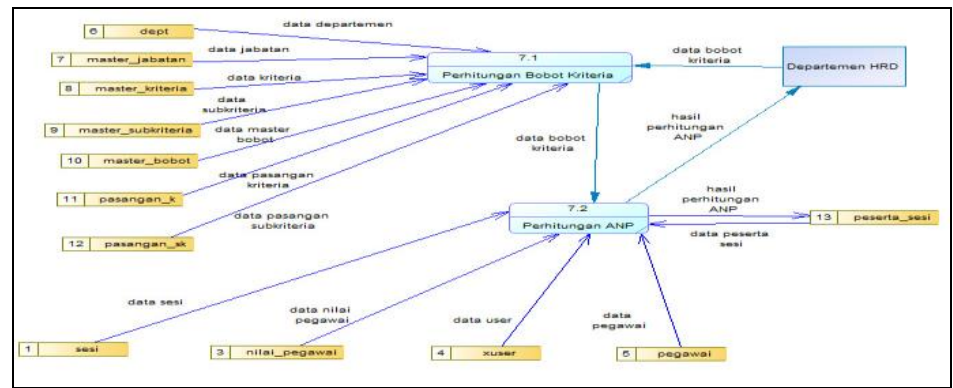

Fig.4. Process of ANP

\section{System Implementation}

After In this chapter, was discussed by the implementation of the system that referred in the design of the database system that was discussed in the Chapter 3. The implementation of the system covered the implementation of the database by using Oracle $10 \mathrm{~g}$ as well as the implementation of the system used Microsoft Visual the Studio .Net 2005.

\subsection{System Testing}

The testing of this system was begun from the page login that will be used to enter the page of the main menu. The user who was registered must put the username and password to the page login to be able to access the page of the main menu. Page login could be seen in the Fig. 5.

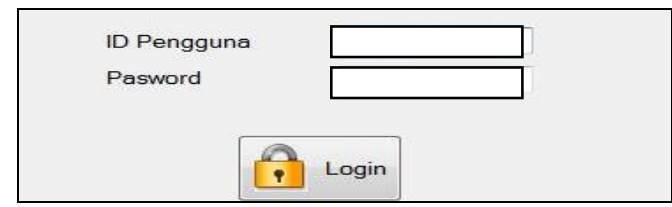

Fig.5. Login Page

To this page the user put the names of the available department in the company as well as the available position in this department, where the position came from the position master. This page could be seen in the Fig. 6.

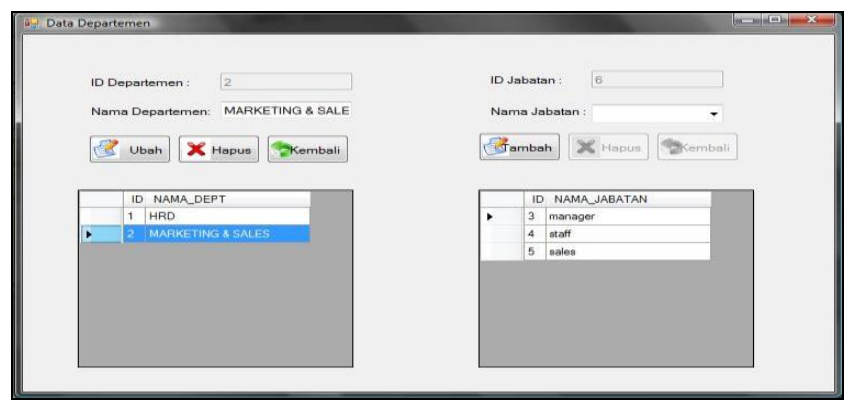

Fig.6. Input Master Department Data 
To this page the user put the names of the available position in the company. This page could be seen in the Fig. 7(a). To this page the user put biodata complete from the prospective official. This page could be seen in the Fig. 7(b).
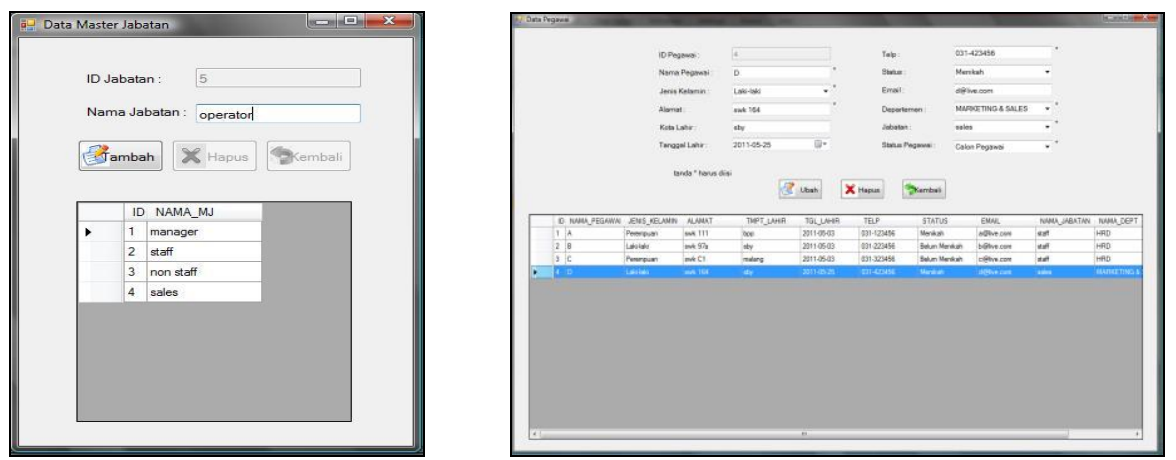

Fig.7. (a) Input Master Occupation Data, (b) Input Candidates Data

To this page the user put the names of the criterion for the ANP could be seen in the Fig. 8(a). To this page the user put the names of the sub-criterion along with range the value of the test for the ANP. This page could be seen in the Fig. 8(b).
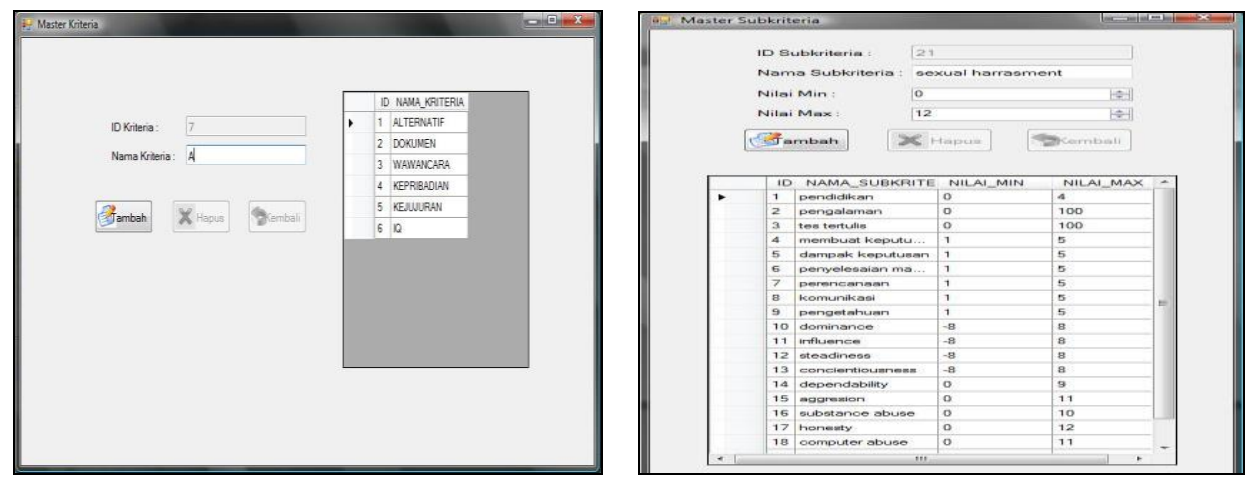

Fig.8. (a) Input Master Criteria, (b) Input Master Sub criteria

To this page the user put the weight master for the ANP could be seen in the Fig. 9(a). To this page the user put the criterion and the sub-criterion that were received in the ANP could be seen in the Fig. 9(b).
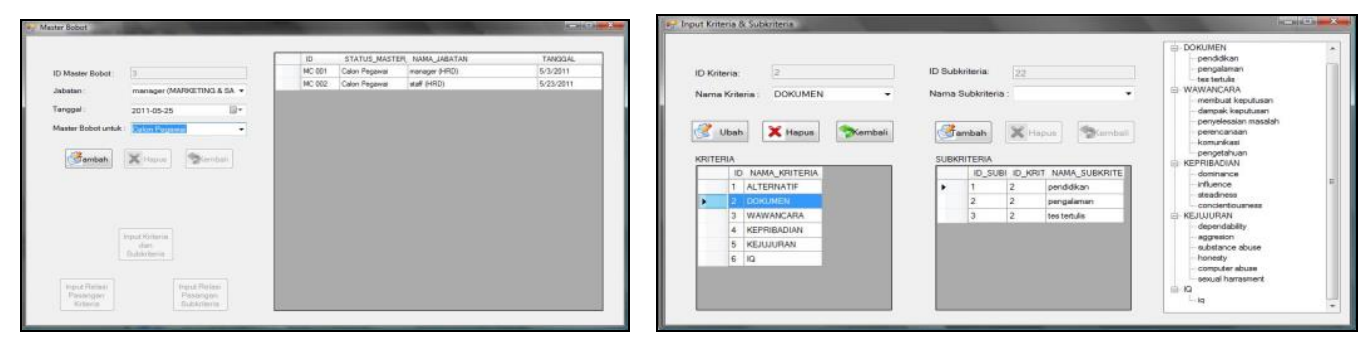

Fig.9. (a) Input Page of Master Quality, (b) Input Page of Criteria and Sub Criteria 
To this page the user put the assessment for the teamed comparison the criterion. This page could be seen in the Fig. 10(a). To this page the user put the session data for the calculation of ANP. Data the session covered the position that will be considered, the weight master who will be used and the list of the official who will be judged. This page could be seen in the Fig. 10(b).
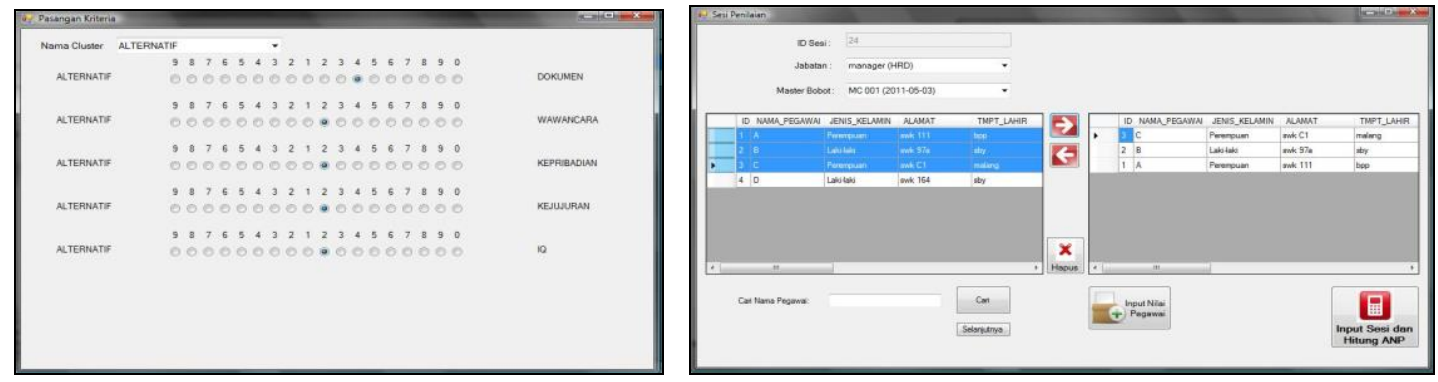

Fig.10. (a) Input Page of Criteria Couple, (b) Input Page of Session

To this page the user put the value of the official in accordance with the sub-criterion from the weight master who was chosen in the page of the session. This page could be seen in the Fig. 11(a). The value of the comparison teamed up cluster the alternative could be seen in the Fig. 11(b).
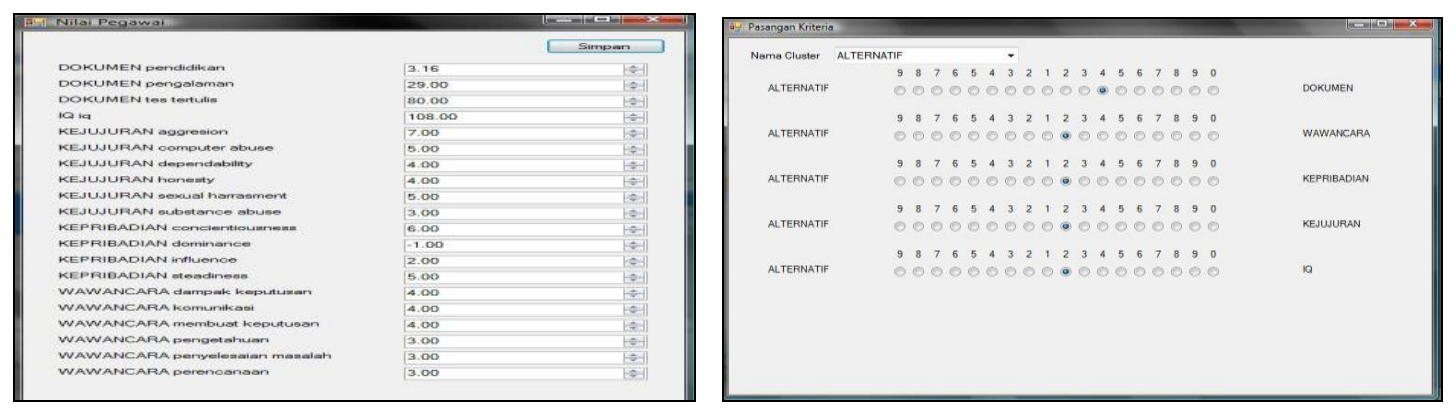

Fig.11. (a) Input Page of the Value From Official, (b) The Value of the Comparison Teamed up Alternative Cluster

This page contained the step in the ANP calculation that was divided into 7 steps in the core. Results of the calculation were put forward in some textbox that contained the name and the value of the end. This page could be seen in the Fig. 12.

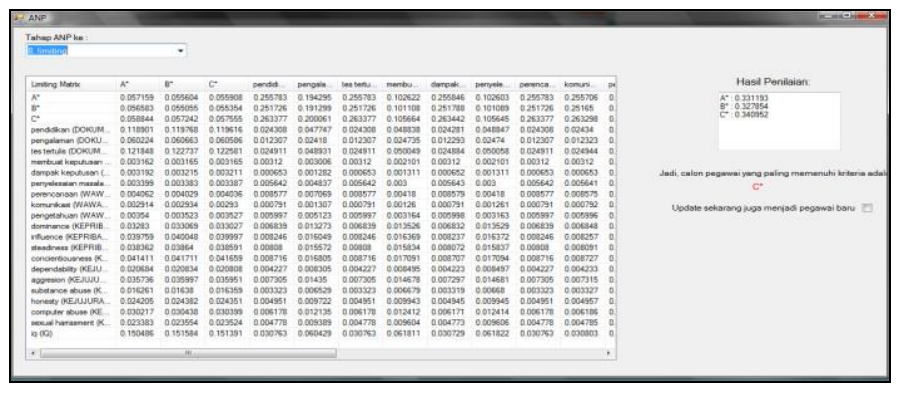

Fig.12. Result From ANP Calculation. 


\section{Conclusions}

From results of the production of the application of the supporting system of the decision in the selection of the prospective official by using the Analytical Network Process method, could be concluded that:

- Results of the ANP calculation that was carried out in this application in accordance with results of the ANP calculation in Super Decision and had the good value of consistency (under 10\%).

- The application system that was developed could help Manager did the selection of the prospective official and the selection of the new official as well as data collection in a structured manner so as to support the balanced and objective assessment.

- This application could help the official's data collection company because of being supported with the database arrangement that structured.

- Needed the development of the user of the interface in accordance with the concept of the interaction of computer humankind in order to be able to facilitate the user in seeing the presentation of the good data.

- Needed the existence of the learning process that was deeper for the user to understand ANP so that increasingly facilitated in selecting the official.

\section{References}

[1] Bayazit, Ozden. (2006). Use of analytic network process in vendor selection decision. Retrieved November 6, 2010, from http://www.knu.edu.tw/lecture/ANP-Vendor section.pdf

[2] Buyukyazici, Murat, Sucu Meral. (2002). The analytic hierarchy and analytic network process. Retrieved November 6, 2010, from http://www.mat.hacettepe.edu.tr/hjms/english/ issues/vol32/abstracts/buyukyazici_sucu.pdf.

[3] Chang, Che-Wei, Cheng Ru Wu, dkk. (2006). Evaluating digital video recorder systems using analytic hierarchy and analytic network processes. Retrieved April 18, 2011, from http://edoc.ypu.edu.tw:8080/paper/mis/Other/24\%202007-IS\%28SCI,\%20EI\%29DVRS\%20AHP\%20ANP.pdf

[4] Cheng, Eddie W. L., Heng Li. (2004). Contractor selection using the analytic network process. Construction Management and Economics. Taylor \& Francis Ltd. (December 2004), 22. 1021-1032. DOI: 10.1080/0144619042000202852. http://www.tandf.co.uk/journals

[5] Meade, L. and Sarkis, J. (1998) Strategic analysis of logistics and supply chain management systems using the analytic network process. Transportation Research Part E: Logistics and Transportation Review, 34(3), 201-15.

[6] Saaty, T.L. (1996) Decision Making with Dependence and Feedback: The Analytic Network Process, RWS Publications, Pittsburgh, PA.

[7] Saaty, Thomas L., Kearns Kevin P. (1985). Analytical planning the organization of systems. Pittsburgh: RWS Publications.

[8] Saaty, Thomas L., Vargas Luis G.. (2006). Decision Making With The Analytic Network Process. United States of America: Springer Science + Business Media, LLC. 


\section{Authors' Profiles}

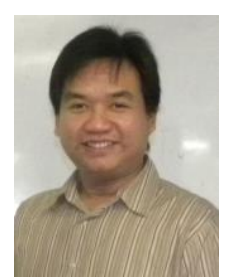

Alexander Setiawan - Obtained his Bachelor Computer degree in Informatics Engineering from Petra Christian University, Surabaya, Indonesia in 2003. He received his master, in Information Technology from Gadjah Mada University, Yogyakarta, Indonesia, in 2008. Now, he served as Assistant Professor and a lecturer in the Department of Informatics Engineering at Petra Christian University, Surabaya, Indonesia. His primary research interest are in software engineering, business intelligent, management information system, and human computer interaction.

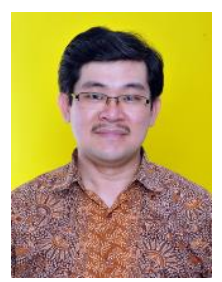

Andreas Handojo - Obtained his Bachelor of Electrical Engineering degree in Electrical Engineering Department from Petra Christian University, Indonesia in 1999. He received his master, in Master of Technology Management from Institute of Technology Sepuluh Nopember, Indonesia, in 2007. Now, he served as Associate Professor in Informatics Engineering Department at Petra Christian University, Indonesia. His primary research interest are in management information system, supply chain management, business intelligent, and mobile device application

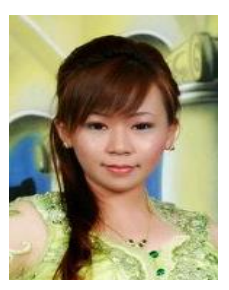

Olivia Gozali - Obtained his Bachelor Computer degree in Informatics Engineering from Petra Christian University, Surabaya, Indonesia in 2011.

How to cite this paper: Alexander Setiawan, Andreas Handojo, Olivia Gozali,"The Development of Officer Selection System using the Method of Analytic Network Process (ANP) at Pharmacy Company", International Journal of Engineering and Manufacturing(IJEM), Vol.6, No.2, pp.1-9, 2016.DOI: 10.5815/ijem.2016.02.01 